\title{
THE EFFECT OF TEACHERS' COLLABORATIVE NETWORKS ON INNOVATIVE SCHOOL CLIMATE AND THEIR INDIVIDUAL INNOVATIVENESS
}

\author{
Efstathios Xafakos ${ }^{1 i}$, \\ Stavroula Kaldi', \\ Aikaterini Vassiou ${ }^{3}$, \\ Vasileios Stavropoulos ${ }^{4}$, \\ Lampros Papadimas ${ }^{5}$, \\ Anastassios Maratos ${ }^{6}$, \\ Alexia Stavrianoudaki ${ }^{7}$, \\ Vassiliki Tzika ${ }^{8}$, \\ Konstantinos Mastrothanasis ${ }^{9}$ \\ 1,5,6,7,8PhDc, Department of Primary Education, \\ University of Thessaly, \\ Volos, Greece \\ 2Professor, Department of Primary Education, \\ University of Thessaly, \\ Volos, Greece \\ ${ }^{3} \mathrm{PhD}$, Department of Primary Education, \\ University of Western Macedonia, \\ Greece \\ ${ }^{4} \mathrm{PhD}$, Department of Primary Education, \\ University of Thessaly, \\ Volos, Greece \\ ${ }^{9} \mathrm{PhDc}$, Department of Primary Education, \\ University of Aegean, \\ Rhodes, Greece
}

\begin{abstract}
:
The main purpose of the study is to investigate the possible effect of school teachers' collaborative networks on their individual innovativeness and the innovative school climate. In addition, 174 Greek primary school teachers' views were explored about their collaboration networks (three collaboration types), their perceived individual innovativeness, the possible existence of innovative school climate, and the support they received in order to promote and/or produce new ideas and practices. Results showed that most of the participant school teachers belong to two categories of the five in the individual innovativeness scale, the early adopters and the early majority, although $20 \%$
\end{abstract}

i Correspondence: email stathisxafakos@yahoo.com, xafakos@uth.gr 
belongs to innovators. Teachers' collaboration network types affect innovative school climate and their individual innovativeness, but there were not found correlation between innovative school climate and perceived teachers' innovativeness. However, collaborative networks within school have a higher effect on teachers' innovativeness, and innovative school climate can be predicted by the network within school and among schools, as well as by the support that school teachers receive.

Keywords: in-service collaborative teachers' networks, perceived individual innovativeness, innovative school climate, Greek primary schools

\section{Introduction}

Innovation in education, as in all sectors of the economy and society, is essential imperative, as it can lead to greater efficiency and improved quality of education (OECD, 2016). Its role in education is very important. It triggers the passion for exploration and learning and provides students with the tools they need to achieve their goals.

However, despite the positive opinions of researchers about the importance of innovation and the encouraging results, educational systems in general remain largely reluctant to innovate. For this reason, educational researchers wanted to explore methods and strategies that can support and promote innovation in schools and, consequently, the development of individual innovativeness for school teachers and the innovative school climate. Among other things, they explore interactive models, such as collaborative networks. The traditional way of educating and training teachers can be considered obsolete, as it maintains their isolation and does not allow for systematic interaction and exchange of new ideas between teachers.

In the present study, it is initially investigated whether there is some degree of collaborative learning, even informally, such collaborative networks in the Greek educational context cause up to now there are no institutionalized structures to support such networks. Teachers' views on the existence of an innovative climate and their perceived innovativeness are also explored. Furthermore, an attempt was made to investigate whether these networks, as a new alternative way of interacting between school teachers, can contribute to the strengthening of the innovative school climate and their individual innovativeness.

\section{Literature Review}

\subsection{Teachers' collaborative networks}

A "network", according to Moolenaar \& Sleegers (2015, p.11), "can be regarded as the pattern of relationships between educators in a bounded group that reflects their purposive interaction". In the educational context, networks can be developed among school teachers within school, across schools (Moolenaar \& Sleegers, 2015) or among them 
outside school who collaborate through social media. In recent years, teachers' networks have gained considerable interest because they are an important "tool" for their work. In addition, studies have shown that these networks contribute to their professional development (Lieberman, 2000).

Social networks can be defined according to the type of social relationships that exist (Moolenaar, 2010). Thus, according to the kind of relationship that develops between members of an organization, we can distinguish them to "instrumental" and "expressive" networks (Ibarra, 1993). "Instrumental" networks describe the professional relationship of the members of an organization, the mutual supply of ideas and the discussion of work-related issues. On the contrary, relations of expression refer to emotional relationships between members and often refer to social support, which is very important. Expression relationships seem to take time to grow but tend to become more powerful and more stable over time.

The terms that could describe the structure of social networks are three: density, reciprocity, centralization (Moolenaar, 2010). Density refers to the number of social relationships that develop in a network. In a dense network many people are connected, while in a sparse network there are fewer contacts and links between members. Reciprocity in social networks exists when two members are linked to each other and often exchange views and ideas. Centralization refers to persons who have more relationships than others. High network centralization means that a few persons manage to a greater extent the flow of resources (Moolenaar, Sleegers, \& Daly, 2012).

Social relations seem to support knowledge transfer (Uzzi, 1997), as they still provide an opportunity for members of an organization to act and to facilitate access to different kinds of information (Haythornthwaite, 2001; Tenkasi \& Chesmore, 2003). The term "network" in the educational context, according to Moolenaar \& Sleegers (2015, p.11), "can be seen as the framework of teacher relations that reflects their intentional interaction" (at the school level) to a group of school organizations that work for a purpose (when referring to a networking between schools) (Chatzipanagiotou \& Marmaras, 2014; Moolenaar \& Sleegers, 2015).

In recent years, networks have become particularly interesting because they seem to be an important "tool" for the teacher in the contemporary era. In addition, studies have shown that these networks contribute, among others, to the professional development of teachers, as well as to building stable relationships, supporting collective work aimed at achieving specific goals (Lieberman, 2000). Lieberman (2000) also argued that the social networking studies focused in understanding the need to create interschool cooperation structures in order to reduce the isolation of many teachers. Previous studies have shown that interaction with friends and colleagues seems to be meaningful and valuable to teachers (Mintzberg, 1979), and more recent studies suggest that teachers, working together and participating in networks, can contribute to school improvement (Lieberman, 2000; Moolenaar et al., 2012). The way teachers learn from one another has evolved during the past decades, by learning through traditional ways such as the strict 
structured mentoring or the casual conversations in the hallway between associate partners (Clarke, Triggs, \& Nielsen, 2014), to the age of Internet with Social Networking Sites (in which teachers access support online), or private sites offered to teachers by government education departments and universities. According to recent research, it is common for teachers to be members of many different Social Networking Sites, looking for support from their fellow professionals (Mastrothanasis, Zouganeli, \& Zervoudakis, 2017; Mastrothanasis, Katsifi-Charalampidi, \& Zervoudakis, 2017). This practice is recognized to be a significant contributor to job satisfaction, professional development and teacher retention (Ingersoll \& Strong, 2011; McCormack, Gore, \& Thomas, 2006). Searching for support of fellow professionals seems to be critical for a teacher's development, especially for pre-service and early career teachers (Ingersoll \& Strong, 2011). Based on the existing literature we can distinguish three collaborative network types:

a) Collaborative networks within school. It is about developing a framework of social relationships and interactions among school teachers in a school unit. Recently, studies suggested that such a framework of relationships within school may be correlated with teachers' positive perception of school innovation and school change (Daly et al., 2014a,d.; Frank et al., 2004 in Moolenaar, 2015).

b) Collaborative networks among schools. Networks, in this sense, are defined as "the cooperation of at least two school organizations, working together for a common purpose and for reasonable time" (Muijs, Wes \& Ainscow, 2010 in Moolenaar, 2015, p. 11) therefore, an extended framework of social relationships and interactions among teachers in different school units exists in order to promote teacher collaboration. Such collaborative actions, which go beyond traditional norms, are regarded as an effective practice to support professional development and teachers' improvement (Díaz-Gibson, Civís-Zaragoza, \& Guàrdia-Olmos, 2014). Network learning, as reported by Chatzipanagiotou \& Marmaras (2014), as in the case of school networks, is about the ability to learn one school from another, to analyze partner practices, and to develop several joint initiatives that are gradually strengthening community.

c) e-Social networks among school teachers (outside the school). Refers to teachers' networks across the school via internet, in which teachers connect with other people to inform and exchange information, ideas and educational material. In this case, significant benefits arise aiming directly at personal professional development and indirectly at improving the school. E-Social networks, in the educational context, mostly fall into the relationship between teachers (instrumental networks), because their main purpose is to inform and exchange information. Teachers in recent years have been using alternative ways of communication and collaboration, utilizing e-social networking tools such as 
Facebook, Twitter, LinkedIn, etc. (Lee \& McLoughlin, 2010) in order to develop social networking and make their school place known to public.

\subsection{Innovative school climate and individual innovativeness}

Innovative climate can be defined as "the perceptions shared by the members of an organization concerning practices, processes and behaviors that can promote the production of new knowledge and new practices" (Van der Vegt, Van de Vliert \& Huang, 2005 in Moolenaar \& Sleegers, 2010, p. 617). An innovative work environment, according to previous research, may influence the creative expression of individuals (Amabile et al., 1996), in order for the organization to avoid declining and on the contrary, to increase its efficiency (Groth \& Peters, 1999). Researchers conclude that the experience of applying innovative ideas is one of the most important elements of an efficient and successful organization, and it is therefore necessary to cultivate an innovative climate (Nonaka, 1994). The innovative climate affects generating new ideas in organizations and applying them successfully (Mumford, Scott, Gaddis, \& Strange, 2002). Innovation is not merely transmitting, diffusing, or recycling existing knowledge between members. It is also concerned with the transformation of prevailing knowledge and practices of actors as a means to organizational change (Nonaka \& Takeuchi, 1995).

On the other hand, individual innovativeness is defined as "developing, adopting or implementing an innovation by a person himself/herself" (Yuan \& Woodman, 2010 in Coclar, 2012, p. 101). An innovative individual is open to new experiences, is a risk taker, goes after original suggestions, transform the existing information and put new ideas into practice (Leavitt \& Wallton, 1975 in Parlar \& Cansoy, 2017). Fullan \& Pomfret (1977) stated that there was an important connection between the development of teachers and their innovative characteristics. Rogers (1995) classifies individuals into five different categories in terms of their innovation characteristics.

Table 1: Levels of Innovativeness

\begin{tabular}{lc}
\hline Levels of Innovativeness & Range \\
\hline Innovators & $81<$ \\
Early adopters & $69-80$ \\
Early majority & $57-68$ \\
Late majority & $47-56$ \\
Laggard & $46>$ \\
\hline
\end{tabular}

These categories are (Kilicer \& Odabasi, 2010): a) Innovators. The risk takers willing to try something new, b) Early Adopters. They are also innovative but more selective and discreet in adopting innovations, c) Early Majority. The careful and deliberate individuals unwilling to risk time or other resources, d) Late Majority. Those individuals who suspect or resist to change and, e) Laggards. These individuals who are consistent in resisting change (Coclar, 2012, p. 101). 


\subsection{Teachers' collaborative networks, innovative school climate and individual innovativeness}

Research suggests that the development of collaborative networks can benefit an organization (Balkundi \& Kilduff, 2005; Moolenaar et al., 2012). According to this argument, studies in the educational context often emphasize the potential importance of teachers' networks for school improvement, as well as for increasing student performance (Daly, 2010; Penuel, Riel, Krause, \& Frank, 2009 in Moolenaar et al., 2012), although the relationship between student performance and teacher co-operative networks is considered non-linear and indirect (Goddard et al., 2007 in Moolenaar et al., 2012). However, cooperation between teachers can improve their practices in many ways.

In addition, researchers, as mentioned by Moolenaar et al. (2012), focused on the instrumental and expressive relationships associated with the exchange of information and mutual advice among teachers. Recent studies have shown that the density of teacher's network which is the number of relationships, is related to the extent to which teachers are willing to take the risk of improving their school (Moolenaar \& Sleegers, 2010). Principally, educators who seek to increase their social network and social relationships seem to be more willing to change.

Recent research has examined the relation between teachers' network and innovative climate (Moolenaar, Daly, \& Sleegers, 2011), instructional practice and student achievement (Frank et al., 2014; Leana and Pil, 2006; Moolenaar et al., 2012b; Penuel et al., 2012; Pil\& Leana, 2009 in Moolenaar \& Sleegers, 2015, p. 11). It also appears that teachers, who maintain contacts with colleagues and integrate in a tightly connected network, show higher levels of trust towards their colleagues (Moolenaar \& Sleegers, 2010). Both teachers' confidence and innovative climate have been positively correlated with student success (Bryk \& Schneider, 2002; Tschannen-Moran, 2001). Moreover, research has examined the correlation between teachers' network and innovative climate (Moolenaar et al., 2011), instructional practice and student achievement (Frank et al., 2014; Leana and Pil, 2006; Moolenaar et al., 2012b; al., 2012; Pil \& Leana, 2009 in Moolenaar \& Sleegers, 2015, p. 11). Moolenaar et al. (2011) indicated that the more densely connected teachers were in regard to work-related and personal advice, the more they perceived their schools' climate to be supportive of innovation. Moreover, teachers who collaborate with their colleagues become more innovative, while innovative teachers are more willing to collaboration (Cumming \& Owen, 2001).

\subsection{The Greek educational context}

Many innovative actions are taking place in the Greek context, in order to improve the innovative school climate. Ministry of Education encourages school units and teachers to implement innovative programs (Votsi, 2016), such as environmental education programs, European educational programs, as well as training and integration of young people, technologies in the educational process. There is also exists a school activities office in every region, which coordinates the educational programs, as well as encourages 
teachers' participation in them. Furthermore, few years ago, Menon, a school innovation network, was developed to support innovative actions and ideas in school units, which was operated only for a few years and did not continue.

However, these programs are not systematically evaluated through data collection, so as to evaluate both the process and the results of the training programs. In addition, they are not yet systematically disseminated, as there is usually no repository of good practices that have been tested by many teachers.

Also, although there are many new ideas, they are not systematically communicated, because there is a lack of systematic trainings promoting innovation. Furthermore, it seems that the innovative climate is not developing systematically in schools, although there are opportunities, as mentioned above. Usually, teachers do not try new ideas, feeling confident with the security of the practices they already know, believing that only these ones could have an effect. In addition, there are often support from the school unit and resources, as well as the opportunity for teachers to work together systematically in order to exchange and try new ideas and practices. School principal's role and support are very important in this direction. Also, there is a lack of time and the curricula are inelastic (Spyropoulou, Vavouraki, Koutra, Louka \& Bouras, 2007).

In conclusion, there are opportunities for the implementation of innovative ideas, as a suitable supportive framework should be formed in the school, to promote these ideas and the teachers' interaction. As mentioned, collaborative networking generates ideas and this is exactly what is being explored in this paper, whether those in charge should be oriented towards the development of collaborative networks.

\section{Significance of the study}

Although there is an important body of literature on the social networking of educational surveys (e.g. Daly, Chrispeels, \& Moolenaar, 2011; Moolenaar, 2010), empirical evidence is still limited more specifically as regards the relation between teachers' networks, their individual innovativeness, the support they receive for innovative action and innovative school climate.

In the international literature, studies focus on either the innovative school climate or individual innovativeness, however research investigating the relationship among them has not been found. Nevertheless, the main point in previous studies is that an innovative work environment may influence the creative expression of individuals (Amabile et al., 1996), in order for an organization to avoid fading and increase its efficiency instead (Growth \& Peters, 1999).

Given the importance of networks in teachers' work, searching the relationship between teachers' networks, individual innovativeness and innovative school climate could expand scientific knowledge on teachers' social networks and innovative school climate. 


\section{Focus of the Study}

Based on the above, an attempt was made to investigate whether the informal collaborative teachers' networks, if it exists and according to their views, contributes to the development of their individual innovativeness and the innovative school climate.

The study also focuses on the following:

1) exploring teachers' instrumental networks (Ibarra, 1993) at three levels (within school, across schools and among teachers from different geographical areas),

2) exploring the levels of teachers' innovativeness, and

3) investigating the possible association between teachers' networks, their individual innovativeness, the support they receive for innovative action and innovative school climate. More specifically, it aims to investigate whether the teachers' networks affect the development of their individual innovativeness, as well as the growth of the innovative school climate.

\section{Method}

Self-administered questionnaires were completed by 174 primary school teachers using the convenience sampling technique. Participants were from rural and urban schools in Greece.

Table 2: Participants' characteristics

\begin{tabular}{llc}
\hline Characteristics & Categories & $\%$ \\
\hline Gender & Male & $24 \%$ \\
& Female & $76 \%$ \\
Age & $\leq 30$ years & $45.4 \%$ \\
& 31-40years & $23.6 \%$ \\
& 31-50years & $18.4 \%$ \\
Diploma & $>50$ years & $12.6 \%$ \\
& Bachelor & $54.5 \%$ \\
& Master degree & $42.5 \%$ \\
& Doctoral degree & $3.0 \%$ \\
\hline
\end{tabular}

Questionnaires included a Likert type scale with 48 items measuring different aspects of teachers' views about their networks, individual innovativeness, innovative school climate and the perceived support teachers receive for innovative practices. The instrument was based on four scales.

The first one was developed by Moolenaar et al. (2010) and it measures the innovative school climate (six items). Thus, one composite variable for innovative school climate was produced.

The second one was developed by Hurt, Joseph and Cook (1977), adopted by Coclar (2012), and it measures teachers' individual innovativeness (19 items). The original scale included 20 items, however for the purpose of this study one item was not 
used. In order to measure perceived teachers' innovativeness, we followed three steps: Step 1: We added the scores for negative items 4, 6, 7, 10, 13, 15, 17, 19. Step 2: We added the scores for positive items 1, 2, 3, 5, 8, 9, 11, 12, 14, 16, 18. Step 3: We completed the following formula: II $=42+$ total score for Step 2 - total score for Step 1 . Therefore, there was a composite variable produced for individual innovativeness.

Table 3: Factors and loadings of teachers' collaborative network types $(\mathrm{N}=174)$

\begin{tabular}{lc}
\hline Factors/Questions & Factor loadings \\
\hline Collaborative networks within school $(\alpha=.882)$ & .810 \\
\hline $\begin{array}{l}\text { I discuss with my colleagues, within school, about pupil's achievement, in order to } \\
\text { improve my teaching practices. }\end{array}$ & .771 \\
$\begin{array}{l}\text { I work and collaborate with my colleagues, within school, to help our pupils. } \\
\text { I often engage in professional dialogue, within school, where we examine with my } \\
\text { colleagues' different ideas and opinions. }\end{array}$ & .761 \\
$\begin{array}{l}\text { I often turn to my colleagues for advice. } \\
\text { We exchange, within school, educational information as well as we share new }\end{array}$ & .710 \\
$\begin{array}{l}\text { educational practices. } \\
\text { We work all together as a team in my school. }\end{array}$ & .659 \\
$\begin{array}{l}\text { We often exchange between us educational material (either in person or via email, } \\
\text { Facebook). }\end{array}$ & .646 \\
$\begin{array}{l}\text { I like to share ideas and information with my colleagues at school on how to become } \\
\text { more effective. }\end{array}$ & .642 \\
$\begin{array}{l}\text { We arrange informal meetings with my colleagues in the school to discuss } \\
\text { educational issues on extra working hours. }\end{array}$ & .537 \\
\hline Collaborative networks outside the school ( $\alpha=.692)$ & .405 \\
\hline $\begin{array}{l}\text { I discuss with my colleagues from other schools and exchange educational material } \\
\text { (either live or online). }\end{array}$ & .831 \\
$\begin{array}{l}\text { I discuss with other school teachers from other schools about classroom } \\
\text { management issues. }\end{array}$ & .757 \\
$\begin{array}{l}\text { I have good professional relationships with my colleagues from other schools. } \\
\text { I have several Facebook friends from other schools, who they "upload" very good } \\
\text { and useful educational material, which I also use. }\end{array}$ & .621 \\
\hline $\begin{array}{l}\text { Collaborative networks among schools }(\alpha=.833) \\
\text { We implement, as a school unit, educational programs in partnership with other } \\
\text { schools. }\end{array}$ & .582 \\
$\begin{array}{l}\text { We plan and organize, as a school unit, joint actions with other schools (educational } \\
\text { visits, etc.). }\end{array}$ & .828 \\
We share good practices, as a school unit, with other schools. & .821 \\
\hline
\end{tabular}

The third one is a self-constructed instrument that assesses which collaborative network type school teachers use the most (17 items). This instrument is based on literature about instrumental collaborative networks (Ibarra, 1993). Following exploratory factor analysis of the 17 items, three different attitudinal dimensions (subscales) were identified: a) collaborative networks within school (Cronbach's $\alpha=.88$ nine items), b) collaborative networks among teachers from different areas (Cronbach's $\alpha=.69$, four items), c) collaborative networks among schools (Cronbach's $\alpha=.83$, four items). The last scale 
measures teachers' views about the support they received (e.g. by the school principal, their school counselor, resources) concerning innovative practices and it is selfconstructed, based on the literature (five items, Cronbach's $\alpha=.71$ ).

\section{Results}

The mean scores in the three subscales of collaborative teacher and school networks are between the medium and the high level. Teacher network within and outside the school are rated in a high level whereas the school networks are rated in a medium level (Table 4). Moreover, innovative school climate and the support teachers receive are rated in a medium level whereas the individual innovativeness is rated in a high level (Table 4). Therefore, in this study teachers consider themselves as being innovative, nevertheless they do not perceive the school climate very innovative and think that they collaborate most with teachers within the school and outside their school. On the contrary teachers do not appear to be positive about the collaboration among schools and the levels of support teacher receive in order to collaborate.

Table 4: Mean scores and standard deviations on teachers' rating of network type, innovative school climate, individual innovativeness and support

\begin{tabular}{lcccc}
\hline & M & SD & N & Cronbach's a \\
\hline NET WITHIN & 3.99 & .74 & 174 & .882 \\
NET OUT & 3.95 & .75 & 174 & .692 \\
NET AMONG SCH & 3.36 & 1.12 & 174 & .833 \\
INNOVATIVE CLIM & 3.31 & .92 & 174 & .921 \\
INDIVIDUAL INNOV & 4.11 & .48 & 174 & .854 \\
SUPPORT & 3.40 & .82 & 174 & .717 \\
\hline
\end{tabular}

The Figure 1 shows that school teachers make greater use of their collaborative network within school and less use of their networking outside of school. In addition, networks among schools exist but to a lesser extent.

Most of the participant teachers belong to two categories of the five in the individual innovativeness scale, the early adopters and the early majority, although $20 \%$ belongs to innovators (Table 3).

A majority of the participants considered themselves as early adopters $(48.27 \%)$ and early majority (23.56\%). Moreover, $20 \%$ of them were found to be innovators. It was also revealed that only $5.74 \%$ of the primary school teachers found themselves as late majority. In addition, a negligible rate was found to be laggard. 
Figure 1: Clear agreement on the extent of collaborative teacher network type

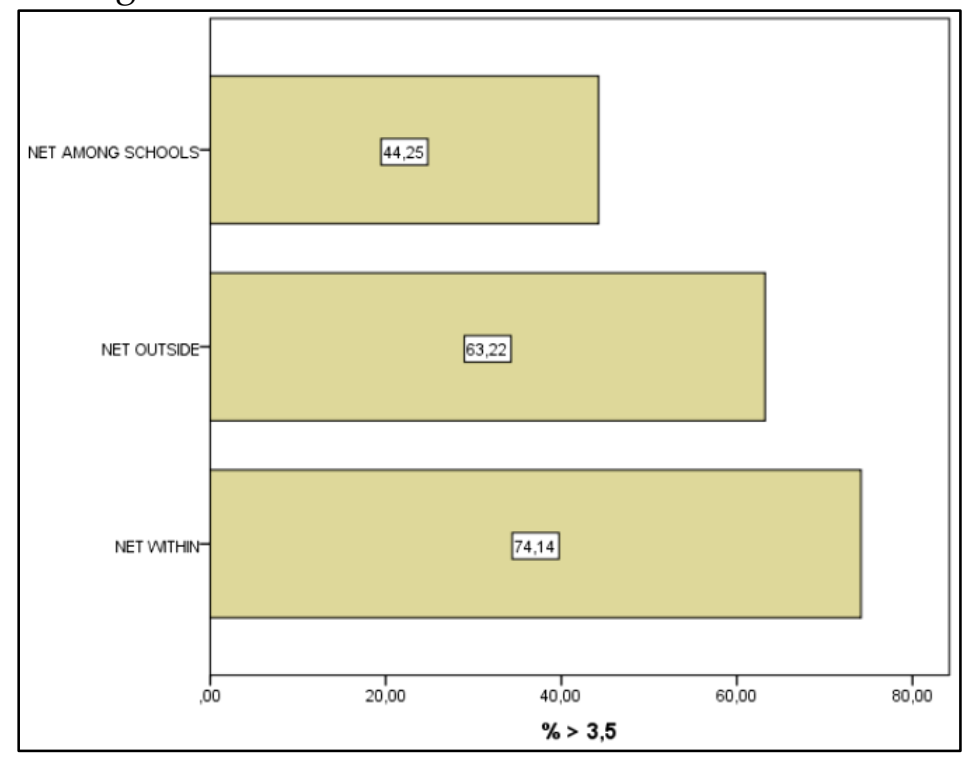

Table 5: Levels of individual innovativeness

\begin{tabular}{clccc}
\hline Levels of Innovativeness & Range & $\mathbf{N}$ & Rate \\
\hline 1 & Innovators & $81<$ & 36 & $20.68 \%$ \\
2 & Early adopters & $69-80$ & 84 & $48.27 \%$ \\
3 & Early majority & $57-68$ & 41 & $23.56 \%$ \\
4 & Late majority & $47-56$ & 10 & $5.74 \%$ \\
5 & Laggard & $46>$ & 3 & $1.72 \%$ \\
\hline
\end{tabular}

Next, Pearson correlations were carried out and statistically significant correlations were found between almost all the composite variables. All three types of teacher networks are related to the innovative school climate, as well as with individual innovation and support. However, correlation between the innovative school climate and the perceived individual innovation of teachers was not found. Therefore, all teachers' collaboration network types affect innovative school climate (see Table 5). All teachers' collaboration network types affect their individual innovativeness, however, networks within the school have a higher effect on their innovativeness.

Table 6: Pearson correlations for teachers' network types, innovative school climate, individual innovativeness and support

\begin{tabular}{|c|c|c|c|c|c|c|c|}
\hline \multicolumn{2}{|c|}{ Levels of Innovativeness } & \multirow{2}{*}{$\frac{\mathbf{1}}{1.00}$} & \multirow[t]{2}{*}{2} & \multirow[t]{2}{*}{3} & \multirow[t]{2}{*}{4} & \multirow[t]{2}{*}{5} & \multirow[t]{2}{*}{6} \\
\hline 1 & NET WITHIN & & & & & & \\
\hline 2 & NET OUT & $.564^{* *}$ & 1.00 & & & & \\
\hline 3 & NET AMONG & $.645^{* *}$ & $.641^{* *}$ & 1.00 & & & \\
\hline 4 & INNOV CLIM & $.607^{* *}$ & $.350^{* *}$ & $.505^{* *}$ & 1.00 & & \\
\hline 5 & INDIVID INNOV & $.344^{* *}$ & $.304^{* *}$ & $.327^{* *}$ & - & 1.00 & \\
\hline 6 & SUPPORT & $.520^{* *}$ & $.274^{* *}$ & $.390^{* *}$ & $.602^{* *}$ & $.220^{* *}$ & 1.00 \\
\hline
\end{tabular}

** $\mathrm{p}<.001$ 
In order to investigate which of the used variables in this study could predict innovative school climate stepwise regression analysis was applied (Table 6). Thus, innovative school climate can be predicted by the network within school and among schools, as well as by the support teachers receive.

Innovative school climate can be predicted at a significant rate $(49.5 \%)$ by networks within school, support for innovation and networks among schools. This indicates that the professional networks among teachers within the school and across schools are very important. Therefore, the innovative school climate can be promoted through established teachers' networks and mutual support amongst them.

Table 7: Stepwise regression for teachers' network types innovative school climate, individual innovativeness and support

\begin{tabular}{lcccccc}
\hline & \multicolumn{5}{c}{ Innovative school climate } \\
Predictor variables & $\mathbf{R}^{2}$ & $\mathbf{B}$ & $\mathbf{S E}$ & $\boldsymbol{\beta}$ & $\mathbf{t}$ & $\mathbf{P}$ \\
\hline Step 1 & & & & & & \\
NET WITHIN & .368 & .749 & .075 & .607 & 10.013 & $<.001$ \\
Step 2 & & & & & & \\
NET WITHIN & .481 & .497 & .080 & .403 & 6.240 & $<.001$ \\
SUPPORT & & .441 & .073 & .392 & 6.081 & $<.001$ \\
Step 3 & & & & & & \\
NET WITHIN & .495 & .379 & .095 & .307 & 3.975 & $<.001$ \\
SUPPORT & & .428 & .072 & .381 & 5.943 & $<.001$ \\
NET AMONG & & .130 & .058 & .159 & 2.219 & .028 \\
\hline
\end{tabular}

\section{Discussion and conclusions}

The present study aimed to explore the views of primary school teachers about their collaboration networking based on the three categories networks proposed by Moolenaar et al (2010), their perceived individual innovativeness, the existence of innovative school climate, and the support they received in order to promote and/or produce innovative ideas and practices. The possible impact of teachers' networks on their individual innovativeness and the innovative school climate was also investigated. Even though the present study is limited due to the choice of collecting data through questionnaires only and due to the application in one educational context, i.e. the Greek one, it does provide however, evidence on how primary school teachers view their own innovativeness in relation to collaborative networks developed, the general innovative school climate and the support they receive in order to collaborate.

Attempting to address the first two research questions of the study we could claim that the participant teachers (a) viewed themselves as quite innovative while recent research has shown that most teachers belong to the group of early majority (Parlar \& Cansoy, 2017) and (b) perceived the collaboration network with colleagues within and outside the school as more frequently used compared to the networks among schools. Thus, teachers seem to claim that they are quite innovative and can collaborate 
individually with colleagues either in the same school or in other schools. This implies that the entire school culture did not appear to have developed innovative school climate and collaboration among schools. The individuality of teachers in this study, more specifically concerning innovativeness and collaboration networks, seems to be very important compared to a community of schools acting upon teachers and innovative practices. However, this individuality does not advance the culture of a school community which could play a significant role in innovativeness. In addition, teachers do not think that the levels of support they receive are high, i.e. from the school principal or other administrative staff in order to act innovatively and collaborate with colleagues. This finding could possibly explain why teachers hold strong views about their individual innovativeness and own collaboration networks compared to the school innovative climate and networks among school.

In addition, an important finding of the present study is that primary school teachers hold a weak positive stance towards the existence of an innovative climate in the school unit they work. This finding is also confirmed in the research by Moolenaar et al. (2010). From the outcomes on the present study many teachers consider themselves as being quite innovative. Previous research, however, shows that a high level of individual innovativeness is not enough for cultivating and maintaining an innovative school climate which is also confirmed in this study due to the lack of any correlation found between the innovative school climate and the perceived individual innovation of teachers. This is also connected to the fact that there is a neutral assessment of the support about innovative actions that teachers get from school principals although previous studies have highlighted the importance of the school principal's role in facilitating innovation (Chesler, Schmuck, \& Lippitt, 1963; Heissenberger \& Heilbronner, 2017). From that it could be also explained why many innovative actions, mainly concerning classroom instruction, remain active within the classroom and are not always known to colleagues. Moreover, the teacher acting in the secure and isolated for him/her classroom environment protects him/her from being exposed to colleagues' views and evaluation (Gaikwad \& Brantly, 1992; Cookson, 2005), a fact that could also explain the high levels of stated individual innovativeness from the part of the teachers.

Concerning the third research question, from the outcomes of the present study teacher networking within and outside the school correlates significantly with the innovative school climate therefore teacher networking has an effect on the innovative school climate. Also, teacher networking affects individual innovativeness nevertheless, there was not directly any correlation between innovative school climate and individual innovativeness. The correlation could be implied but it is not confirmed through the statistical data. One would also expect that as long as teachers have developed collaborative networks within and outside the school they work, then their individual innovativeness would be positively related to the innovative school climate. However, although the idea of networking is positively assessed by the participant teachers, this does not seem to be sufficient to allow the dissemination of innovative ideas and practices 
to colleagues or/and their use by other teachers and thus, create an innovative school culture. A possible explanation could be the fact that teacher networking is often limited to instructional needs (i.e. curriculum, teaching practices) and not to innovative ideas and practices which would require the support of different agents such as colleagues, school principals or other administrative staff in the local education authorities. In addition, the reasons for this mismatch in the findings i.e. the lack of any correlation in the statistical data between innovative school climate and individual innovativeness would be further elaborated with the use of qualitative data through which the so-called teachersinnovators as classified by the levels of individual innovativeness could provide evidence about the possible association between their own innovativeness and the creation of an innovative school climate. In other words, further qualitative data could demonstrate the level to which innovators can actually affect the development of an innovative school climate in the school unit they work.

Another outcome to note in this study refers to the correlation between individual innovativeness and teacher networking. This finding relates directly to previous research outcomes which indicated that teachers who collaborate with colleagues become more innovative, while innovative teachers are more willing to collaboration (Cumming \& Owen, 2001). From this we could conclude that innovative teachers are more willing to collaborate and develop networks with colleagues because they look for new ideas and teaching practices.

Concluding, in the present study a model of relations between individual innovativeness, innovative school climate, the support teachers receive for innovative actions and teacher collaborative networks can be outlined. Teacher high individual innovativeness level does not relate with the innovative school climate, but it relates positively with the teachers' networks developed within and outside the school. Thus, teacher networks can enhance teacher individual innovativeness. The innovative school climate can be predicted by the teachers' network within the school and the network developed among schools as units as well by the support teachers receive in order to act innovatively. Therefore, regardless of the level of individual innovativeness for each teacher what seem to be the most important factors to develop innovative school climate in a school unit are (a) the collaboration among teachers in the school unit, (b) the high levels of support provided to teachers in order to act innovatively and (c) the development of a collaborative community of schools within an education district. Teacher individual innovativeness seems to be the oasis in the desert which is not enough on its own to supply schools with innovative climate compared to the other important factors mentioned above that can play a vital role in developing innovative school climate.

Finally, we can propose for further research in the future the investigation of teachers' perceptions about the concept of innovation, their views about the limitations for innovative practices in the Greek educational context and about possible reasons for the school climate not developing to be innovative, although school conditions in some 
cases could be claimed to be promising for developing a positive innovative school climate. An important implication for further study could also be the views of teachers classified in the levels of innovativeness about the effect of their own individual innovativeness on the development of an innovative school climate.

\section{Conflict of Interest Statement}

The authors declare no conflict of interest.

\section{About the Authors}

Efstathios Xafakos is a primary school teacher and a PhD Candidate Researcher in Organization and Administration of Education at the department of Primary Education, University of Thessaly, Greece.

Dr. Stavroula Kaldi is a Professor in Pedagogy and Instruction in the Department of Primary Education at the University of Thessaly, Greece. She has extensive experience in teaching and research in higher education in Greece. Her research interests include project-based learning, co-operative learning, intercultural education, teacher education and teacher professional development.

Aikaterini Vassiou has a PhD in Educational Psychology and a Post Doc in School Psychology and Counseling. She belongs in academic staff in the Department of Primary Education at the University of Western Macedonia, Greece.

Vasileios Stavropoulos, M.Ed., M.Sc., holds a PhD in Educational Administration and Research Methodology. He has an 18-year experience as primary education teacher, seven of them as vice-principal, principal and teachers' district coordinator. He is a tutor at pre-service teachers' training and postgraduate courses.

Lampros Papadimas is a primary school teacher and a PhD candidate in Theory and Didactics of History (University of Thessaly). He studied Pedagogy (BA), Educational Administration and Management (Med) in University of Thessaly. He also made several presentations at conferences, on thematic aspects relevant to (a) educational history, (b) didactics of history, (c) curriculum, (d) school climate.

Anastassios Maratos is a primary and high school teacher. He has a B.A. degree in the Department of Philosophy of the University of Ioannina, a B.A. degree in the Department of Primary Education of Thessaly, a M.Sc. in Educational Administration and Management and he is currently a PhD student in Educational Administration and Management.

Vassiliki Tzika is a PhD Candidate Researcher in the Department of Primary Education at the University of Thessaly, Greece and a primary school teacher. Her research interests focus upon cross-curricular skills, life-long learning, project-based learning, co-operative learning, student voice and teaching writing texts.

Alexia Stavrianoudaki is a PhD candidate researcher in the Pedagogical Department of Primary Education at the University of Thessaly and a primary school teacher. Her main 
research interest lies in the field of history and in particular the use of inquiry- based learning (IBL) in class.

Konstantinos Mastrothanasis is a $\mathrm{PhD}$ Candidate in the Department of Primary Education of the University of the Aegean. He serves as a primary school teacher as well as a scientific associate of the School of Pedagogical and Technological Education (ASPETE) and the National and Kapodistrian University of Athens.

\section{References}

Amabile, T., Conti, R., Coon, H., Lazenby, J., \& Herron, M. (1996). Assessing the work environment for creativity. The Academy of Management Journal, 39(5), 1154-1184.

Bakkenes, I., de Brabander, C., \& Imants, J. (1999). Teacher isolation and communication network analysis in primary schools. Educational Administration Quarterly, 35(2), 166-202.

Balkundi, P., \& Kilduff, M. (2005). The ties that lead: A social network approach to leadership. Leadership Quarterly, 6, 941-961.

Bryk, A. S., \& Schneider, B. (2002). Trust in schools: A core resource for school improvement. New York, NY: Russell Sage Foundation.

Chatzipanagiotou, P. \& Marmaras, Ch. (2014). School Networking Practices: learning networks as a mechanism to encourage the continued professional development of teachers and managers. In Z. Papanaoum \& M. Liakopoulou, (Eds.). Supporting the professional development of teachers (pp. 151-160). Training Manual. Thessaloniki: Aristotle University of Thessaloniki [in Greek].

Chesler, M., Schmuck, R., \& Lippitt, R. (1963). The principal's role in facilitating innovation. Theory into Practice, 2, 269-277.

Clarke, A., Triggs, V., \& Nielsen, W. (2014). Cooperating Teacher Participation in Teacher Education: A Review of the Literature. Review of Educational Research, 84, 163-202.

Coclar, A. N. (2012). Individual Innovativeness Levels of Educational Administrators. Digital Education Review, 22, 100-110.

Cookson, W. (2005). The challenge of isolation and professional development. Teaching Pre K-8, 36(2), 14-16.

Cumming, J. \& Owen, C. (2001). Reforming Schools through Innovative Teaching. Australian College of Education: Deakin, ACT.

Daly, A. J., \& Finnigan, K. (2010). A bridge between worlds: Understanding network structure to understand change strategy. Journal of Educational Change, 111, 111138.

Daly, A. J., Chrispeels, J., \& Moolenaar, N. M. (2011). A capital investment: The effects of teacher human and social capital on student achievement in improving schools. International Congress on School Effectiveness and Improvement, Limassol, Cyprus. 
Díaz-Gibson, J., Civís-Zaragoza, M., \& Guàrdia-Olmos, J. (2014). Strengthening education through collaborative networks: leading the cultural change. School Leadership $\mathcal{E}$ Management, 34(2), 179-200.

Fullan, M. \& Pomfret, A. (1977). Research on Curriculum and Instruction Implementation. Review of Educational Research, 47(1), 335-397.

Gaikwad, S., \& Brantly, P. (1992). Teacher isolation-loneliness in the classroom. Journal of Adventist Education, 54, 14-17.

Groth, J. C., \& Peters, J. (1999). What blocks creativity? A managerial perspective. Creativity and Innovation Management, 8(3), 179-187.

Haythornthwaite, C. (2001). Tie strength and the impact of new media: Proceedings of the 34th Hawai'i International Conference on System Sciences. Los Alamitos, CA: IEEE Computer Society Press.

Heissenberger, P., \& Heilbronner, N. (2017). The influence of primary school principals' leadership styles on leadership practices. Global Education Review, 4(4), 86-101.

Hurt, H. T., Joseph, K., \& Cook, C. D. (1977). Scales for the measurement of innovativeness. Human Communication Research, 4(1), 58-65.

Ibarra, H. (1993). Personal networks of women and minorities in management: A conceptual framework. Academy of Management Review, 18(1), 56-87.

Ingersoll, R. \& Strong, M. (2011). The Impact of Induction and Mentoring Programs for Beginning Teachers: A Critical Review of the Research. Review of Education Research, 81(2), 201-233.

Kilicer, K. \& Odabasi, H. F. (2010). Individual innovativeness scale (is): the study of adaptation to Turkish, validity and reliability. Hacettepe University Journal of Education, 38, 150-164.

Lee, M. J. W., \& McLoughlin, C. (2010). Beyond distance and time constraints: Applying social networking tools and Web 2.0 approaches in distance education. In G. Veletsianos (Ed.), Emerging technologies in distance education (pp. 61-87). Edmonton, Canada: Athabasca University Press.

Lieberman, A. (2000). Networks as learning communities: Shaping the future of teacher development. Journal of Teacher Education, 51(3), 221-227.

Mastrothanasis, K., Zouganeli, A., \& Zervoudakis, K. (2017). Teacher education in the teaching of mathematics through e-learning communities and its effect on student performance in mental addition calculations (pp. 409-418). In: Sp., Pantazis, E., Maraki, et al (eds.), Proceedings of the 3rd Panhellenic Scientific Conference "Humanities, Education, Society and Political Education", Volume II. Heraklion, Crete: Institute of Humanities and Social Sciences[in Greek].

Mastrothanasis, K., Katsifi-Charalampidi, Sp., \& Zervoudakis, K. (2017). E-learning communities for teacher training and its effect on learning performance of mental subtraction calculations of primary school students. (pp. 990-996). In: K. Papanikolaou et al (eds.), Proceedings of the 5th Panhellenic Conference "Integration 
and Use of ICT in the Educational Process", Athens: School of Pedagogical and Technological Education (ASPETE) [in Greek].

McCormack, A., Gore, J., \& Thomas, K. (2006). Early Career Teacher Professional Learning. Asia-Pacific Journal of Teacher Education, 34, 95-113.

Mintzberg, H. (1979). The structuring of organizations. Englewood, NJ: Prentice Hall.

Moolenaar, N. M. (2010). Ties with potential. Nature, antecedents, and consequences of social networks in school teams. Unpublished doctoral dissertation. The Netherlands: University of Amsterdam.

Moolenaar, N. M., \& Sleegers, P. J. C. (2010). Social networks, trust, and innovation. How social relationships support trust and innovative climates in Dutch Schools. In A. Daly (Ed.), Social Network Theory and Educational Change (pp. 97-114). Cambridge, MA: Harvard University Press.

Moolenaar, N. M., \& Sleegers, P. J. C. (2015). The networked principal. Journal of Educational Administration, 53(1), 8-39.

Moolenaar, N. M., Daly, A. J. \& Sleegers, P. J. (2011). Ties with potential: Social network structure and innovative climate in Dutch schools. Teachers College Record, 113(9), 1983-2017.

Moolenaar, N. M., Sleegers, P. J. C., \& Daly, A. J. (2012). Teaming up: Linking collaboration networks, collective efficacy, and student achievement. Teaching and Teacher Education, 28(2), 251-262.

Mumford, M. D., Scott, G. M., Gaddis, B., \& Strange, J. M. (2002). Leading creative people: Orchestrating expertise and relationships. Leadership Quarterly, 13, 705-750.

Nonaka, I. \& Takeuchi, H. (1995). The knowledge-creating company. How Japanese companies create the dynamics of innovation. Oxford: Oxford University Press.

Nonaka, I. (1994). A dynamic theory of organizational knowledge creation. Organization Science, 5(1), 14-37.

OECD (2016). Innovating Education and Educating for Innovation: The Power of Digital Technologies and Skills. Paris: OECD Publishing.

Parlar, H. \& Cansoy, R. (2017). Examining the Relationship between Teachers' Individual Innovativeness and Professionalism. International Education Studies, 10(8), 1-11.

Rogers, E. M. (1995). Diffusion of Innovations (4 $4^{\text {th }}$ edition). New York: Free Press.

Spyropoulou, D., Vavouraki, A., Koutra, X., Louka, E. \&Bouras, S. (2007). Innovative educational programs in education. PedagogikiEpitheorisi,13, 69-83 [in Greek].

Tenkasi, R., \& Chesmore, M. (2003). Social networks and planned organizational change. Journal of Applied Behavioral Science, 39(3), 281-300.

Tschannen-Moran, M. (2001). Collaboration and the need for trust. Journal of Educational Administration, 39(4), 308-331.

Uzzi, B. (1997). Social structure and competition in interfirm networks: The paradox of embeddedness. Administrative Science Quarterly, 42, 35-67. 
Efstathios Xafakos, Stavroula Kaldi, Aikaterini Vassiou, Vasileios Stavropoulos, Lampros Papadimas, Anastassios Maratos, Alexia Stavrianoudaki, Vassiliki Tzika, Konstantinos Mastrothanasis

THE EFFECT OF TEACHERS' COLLABORATIVE NETWORKS ON INNOVATIVE

SCHOOL CLIMATE AND THEIR INDIVIDUAL INNOVATIVENESS

Votsi, E. (2016). Educational innovation in the Greek school reality and the school unit's autonomy. Education, Lifelong Learning, Research and Technology Growth, Innovation and Economy, 1, 517-523 [in Greek].

Creative Commons licensing terms

Author(s) will retain the copyright of their published articles agreeing that a Creative Commons Attribution 4.0 International License (CC BY 4.0) terms will be applied to their work. Under the terms of this license, no permission is required from the author(s) or publisher for members of the community to copy, distribute, transmit or adapt the article content, providing a proper, prominent and unambiguous attribution to the authors in a manner that makes clear that the materials are being reused under permission of a Creative Commons License. Views, opinions and conclusions expressed in this research article are views, opinions and conclusions of the author(s). Open Access Publishing Group and European Journal of Education Studies shall not be responsible or answerable for any loss, damage or liability caused in relation to/arising out of conflicts of interest, copyright violations and inappropriate or inaccurate use of any kind content related or integrated into the research work. All the published works are meeting the Open Access Publishing requirements and can be freely accessed, shared, modified, distributed and used in educational, commercial and non-commercial purposes under a Creative Commons Attribution 4.0 International License (CC BY 4.0). 